\title{
SWITCH city water balance: a scoping model for integrated urban water management
}

\author{
Rae Mackay $\cdot$ Ewan Last
}

Published online: 2 November 2010

(C) Springer Science+Business Media B.V. 2010

\begin{abstract}
Climate shifts, environmental degradation, aging infrastructure, energy adaptation and population growth are impacting many cities worldwide and will force changes to the way water is managed in the future for most cities around the world. To help meet these challenges, the SWITCH European Framework VI project is developing decision support tools to assist city stakeholder communities to scope future options for integrated urban water management (IUWM). City Water Balance (CWB) is one of several simulation tools being developed within SWITCH as part of the City Water integrated knowledge base system/decision support system. CWB is a scoping tool developed to allow the rapid assessment of alternative water management strategies for a city. The tool outputs indicator data on water demand, quality, energy consumption, and simplified life-cycle cost. The data requirements of City Water Balance allow a model to be established quickly from extant spatial mapping. It advances previous work of Integrated Urban Water Management (IUWM) scoping models in two ways. The first is the integration of natural systems more fully into the urban water cycle description. The second is the extension to address energy consumption as well as
\end{abstract}

R. Mackay $(\bowtie) \cdot$ E. Last

School of Geography Earth and Environmental Sciences,

University of Birmingham, Edgbaston,

Birmingham B15 2TT, UK

e-mail: r.mackay@bham.ac.uk life cycle costs. The initial application of the model to Birmingham (UK) using historical data for verification and validation has provided a valuable illustration of the effectiveness of the model.

Keywords Decision support - Scoping model · Urban water management $\cdot$ Life cycle cost

\section{Introduction}

A main goal of the EU funded SWITCH integrated project is to promote a paradigm shift from sectoral management of urban water systems in which the three operational domains: water supply, waste water and stormwater are managed largely separately to integrated urban water management where all components of the water cycle in a city are treated as potential resources and are managed accordingly. In this context an important objective is the identification of sustainable and effective water management systems for the 'city of the future'. To achieve this objective the SWITCH project consortium has been working to improve the scientific basis for the development and management of alternative urban water systems and to ensure that they are robust under a range of future global change pressures.

One product of SWITCH is City Water, a Knowledge Base System/Decision Support System (KBS/ DSS). City Water builds on past and contemporary work in the field of Decision Support and Scoping 
models for assessing alternative management options for urban water (AQUACYCLE, UVQ, UWOT, MULINO, HARMONIT, DAYWATER). However, it departs from these in several ways that are specific to the SWITCH project and to the Learning Alliance environment for participatory planning. In particular:

- significant weight is given to the integrated exploitation of the natural environment as one possible contribution to the development of a sustainable future.

- contributions are made that deal with aspects of the regulatory environment, the legal frameworks for decision making and with the existence and location of historical data.

- a broad range of time and space scales are covered that permit, for example, life cycle costing (either energy or financial) over long times and local flooding over short times. It is also applicable to the exploration of the evolution of the landscape of a city and the transitioning of the water system.

City Water Balance forms part of the City Water KBS/DSS and is a scoping model for simulating the dynamic balances of water, energy and pollutants at the city scale. It works on a daily time step over decadal periods and can explore water and wastewater stresses in response to climate change and changing urban populations under a range of strategic technical options for improved IUWM. Five indicators, characterizing neighbourhood or city-scale conditions, are currently derived for output: water demand/supply ratios; wastewater production; water quality; life cycle energy and life cycle cost.

\section{City water balance: model concepts}

A primary design goal for City Water Balance $(C W B)$ was that it should be applicable to cities where mapping and monitoring are underdeveloped as well as to cities possessing detailed knowledge of their water and wastewater systems. The key idea for City Water Balance is that it is an urban hydrological modelling system that works at the lowest spatial and temporal resolution commensurate with the provision of meaningful indicator outputs for the comparison of different water management options.

\subsection{Spatial and temporal resolution}

To model land use within the cityscape, the unit block concept adopted for the water balance model, Aquacycle (Mitchell et al. 2001) is employed within $C W B$. The unit block describes the storage, use and transmission of water of easily recognized land uses (e.g. houses with gardens, apartment blocks, hospitals or golf courses). Fundamental attributes of the unit block are pervious/impervious areas, water demand profiles and pollutant loads (Mitchell et al. 2001; Mitchell and Diaper 2005). A library of forty-nine unit block types has been created based on data from the United Kingdom. This will expand as new types are identified during the application of the model to other SWITCH demonstration cities.

The city waterscape is characterised for input to CWB by mapping the mosaic of neighbourhoods containing similar unit block types. Neighbourhoods can be identified using a combination of available aerial photography and road maps, with some additional ground truthing: a city can be mapped quickly through this approach. $C W B$ departs from the modelling of water transfers between neighbourhoods adopted by Aquacycle and models lateral flows using a network of subcatchments formed by the wastewater and natural drainage networks. Subcatchments may contain any number of whole neighbourhoods. The use of subcatchments to aggregate lateral flows from neighbourhoods means that the neighbourhood areas can be based solely on the pattern of land use. This enables more rapid mapping of the water demands across a city as well as improving the representation of the wastewater and stormwater networks at the city scale.

A daily timestep was selected as appropriate for modeling the transient behavior of the city water system under changing land use, water management strategies and climate scenarios. Although this level of aggregation results in the loss of flow variations needed for flood analysis, it provides sufficient information (Makropoulos et al. 2008) for the comparison of different water management options, especially for the long-term simulations necessary for sustainability assessments.

\subsection{Mains water}

Mains water is modelled as an external supply. The mains water demand is calculated as the sum of the neighbourhood demands that are not met by local or 
decentralised supply schemes. A proportion of the supply is lost as leakage within the modelled region. Mains water is supplied at fixed contaminant concentration and with a fixed energy and economic cost attached to it. This simplified approach to the modelling of the mains supply has been adopted as cost, energy and contaminant data for water supply are typically more easily gathered as aggregate values and mains source modelling is avoided. Water demand input to $C W B$ is based on land use in terms of per capita demand or per unit area demand for different water use requirements (Hunt and Lombardi 2006). $C W B$ can simulate the impact of seasonal occupancy to account for population influx through tourism at certain times of the year or migration outwards at times of high temperatures (Manoli 2009). The application of Aquacycle in the early stages of the SWITCH project to Athens proved to be problematic as it was unable to simulate demand during the summer for this reason (Karka et al. 2006). For residential blocks an alternative model for the estimation of indoor demand is available. This has been based on ideas adopted in UWOT (Makropoulos et al. 2008) where the demand profile is built from a selection of water using appliances (bath, W.C., kitchen tap etc.). A library of default options is available with $C W B$, to which the user can add their own appliances, if required.

\subsection{Runoff}

There are five types of surface that can generate runoff in $C W B$ : roof, pavement, garden, road and Public Open Space. In each neighbourhood, the degree to which these surfaces are connected to the piped stormwater system varies. To address the issue of overland flow outside the sewer network $C W B$ uses the idea of effective areas, originally introduced in Aquacycle (Mitchell et al. 2001). The effective area is defined as the proportion of the total area of an impermeable surface (roof, paved, road) generating runoff that goes directly to the stormwater system. Runoff from non-effective areas flows onto nearby pervious space or sustainable urban drainage systems (SUDS), if available.

\subsection{Natural systems}

A single layer two dimensional areal groundwater system can be modeled beneath a city. The groundwater is fully coupled to the neighbourhoods and surface water features. Rivers, lakes and ponds can all be represented as discrete water bodies. Rivers are split into reaches. Backwater or reverse flows in a river cannot be simulated. External water supplies to surface water bodies are simulated as simple source terms. Stormwater or wastewater subcatchments may discharge to the surface water network.

\subsection{Contaminants}

Modeling of contaminants follows the concepts outlined in $U V Q$ (Mitchell and Diaper 2005). In any simulation up to four pollutant species can be modeled concurrently. Contaminant inputs are represented as concentrations in input streams and as loads added during indoor water use. Contaminants are modeled conservatively, with no conversion or degradation. Previous work has shown that more detailed modeling of contaminant interactions requires additional site specific data and increases the complexity of the model without necessarily improving the accuracy (Mitchell et al. 2003). When contaminated water flows combine they become well mixed.

\subsection{Energy and cost}

For each of the decentralised water management (WM) options in $C W B$, simplified life cycle energy and cost stand-alone spreadsheet models have been developed, which serve as a technology library to $C W B$. The cost and energy for supply and treatment using the conventional, centralised piped systems uses published average energy and cost values per cubic meter of supplied and treated water. Lifetime energy use is calculated as the sum of the embodied energy of all component parts, diesel used in transportation and by construction plant, diesel used in maintenance and operational costs (e.g. electricity for pumps and embodied energy of chemical treatment). Whole life cost is calculated as the sum of the capital, construction, maintenance and operation costs. Costs incurred throughout the lifetime of the asset are reduced to net present value. For a number of SUDS (porous pavement, porous asphalt, filterstrips, soakaways, ponds and swales) only the lifetime energy use is calculated since the lifetime cost for these options is well-documented (WoodsBallard et al. 2007). Energy and cost data were 
obtained from suppliers' specification manuals and literature (e.g. Materials embodied energy (Hammond and Jones (2008)); Diesel consumption (DEFRA 2007; SPON 2005); SUDS dimensions (WoodsBallard et al. 2007); Pump operation energy (Hunt and Lombardi 2006; Woods-Ballard et al. 2007); Cost (SPON 2005))

\subsection{Water management options}

$C W B$ allows exploration of the sustainability of a variety of water management options at different spatial scales. These are green roofs, rainwater harvesting, wastewater recycling, septic tanks, borehole abstraction, porous paving, porous asphalt, swales, filter strips, soakaways, retention ponds and detention basins. Inflows to SUDS are direct precipitation and runoff. Outflows are evaporation, infiltration, throughflow, and overflow. Flow along conveyance swales is modelled by a normal depth approximation using the swale cross-section and a manning's resistance coefficient.

\section{Birmingham study area}

Initial verification and validation of $C W B$ was carried out for Birmingham (United Kingdom). The main pressures on water in Birmingham, and the West Midlands are similar to many other major Western European cities and can be divided into three distinct areas: surface water management and quality; groundwater protection and management and flood risk. Increasing population is leading to an increased demand for potable water and is increasing flows and loads in the sewerage system and wastewater treatment plants. It is predicted that the West Midlands population will increase by $6.6 \%$ between 2003 and 2023.

To gain insights into alternative futures for Birmingham, $C W B$ has been used to model the wastewater drainage area for the major wastewater treatment plant at Minworth, which covers most of the city. Six thousand neighbourhoods have been mapped across the Minworth catchment area comprised of 49 different unit block types (Fig. 1). These fall within 27 subcatchments that are matched to the Drainage Study Areas used by Severn Trent Water

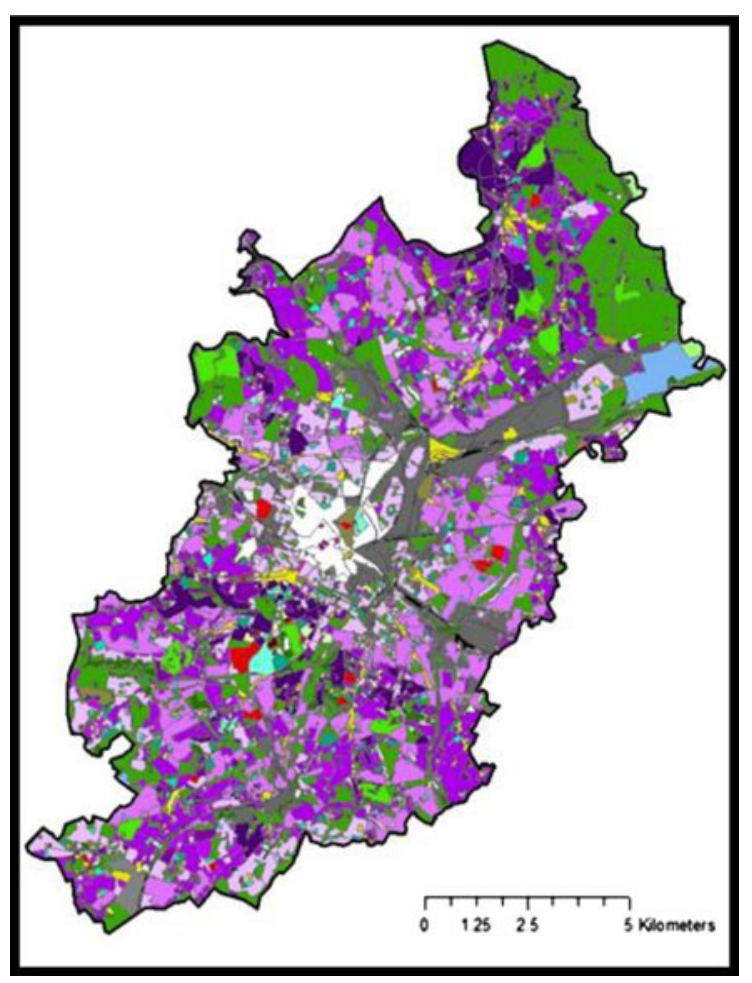

Fig. 1 Landuse map of the Birmingham Study Area. Pink/ purple (dark grey) is residential; grey includes industry, roads and railways; green is vegetated area; white is city centre; and brown/yellow is commercial. (Color figure online)

for its management of the wastewater network (Fig. 2). In addition, 271 district metering areas are identified that define the water demands across the city. The majority of the water supplied to the city is imported from the Elan valley, 120 kilometres from Birmingham. Detailed data characterising the water consumption for all district metering areas and wastewater/stormwater flows for selected short periods of several months for different locations across the city have been provided by Severn Trent spanning the years 2004-2009. Using these data, an iterative process of model calibration and validation was adopted both to verify the attributes of the model components and to learn more about the behaviour of the water supply and waste water collector systems. Certain features of the system assumed a priori for the setting up of the model, particularly in relation to changes in leakage from the water supply network and surface and foul sewer mixing were revised during this process. 


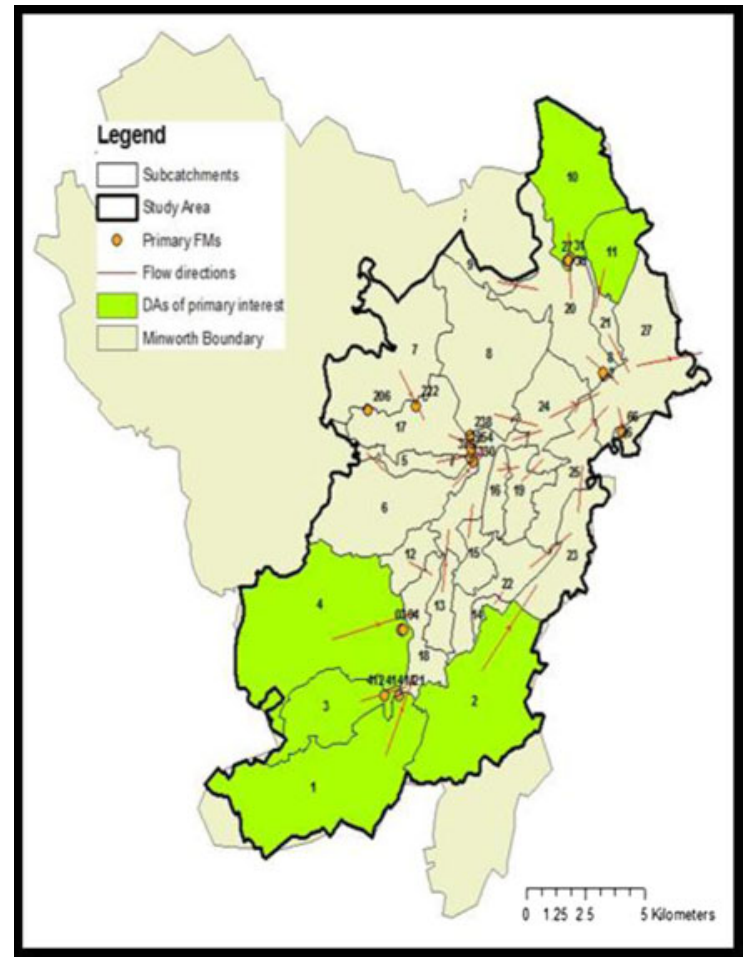

Fig. 2 Minworth WWTP catchment split into 27 subcatchments in the Study Area. Flow monitoring points on the sewerss of key interest are shown as circles

\section{Calibration/validation}

Figure 2 shows the drainage areas used for flow calibration. They are situated on the boundary of the Minworth Catchment and were preferred for the initial calibrations because there is no flow into them from upstream drainage areas. After calibration of the water supply to the 2008-2009 water records from Severn Trent (Fig. 3), calibration of stormwater and wastewater flows was undertaken.

Flow monitoring point FM412 (Fig. 2) is a $750 \mathrm{~mm}$ diameter foul sewer that was monitored during a 2 month period (February to April 2007) (STW, 2009). It is located at the outflow point from Subcatchment 3. In the application of the Australian model UVQ to Doncaster (UK), Rueedi and Cronin (2005) calculated that $1 \%$ of stormwater runoff inflows into the foul network. If this value is applied to the Birmingham model then $C W B$ fails to match the fluctuations in the observed data. By increasing the inflow to $25 \%$ a much better match was obtained. The match remains imperfect, but the timing of the

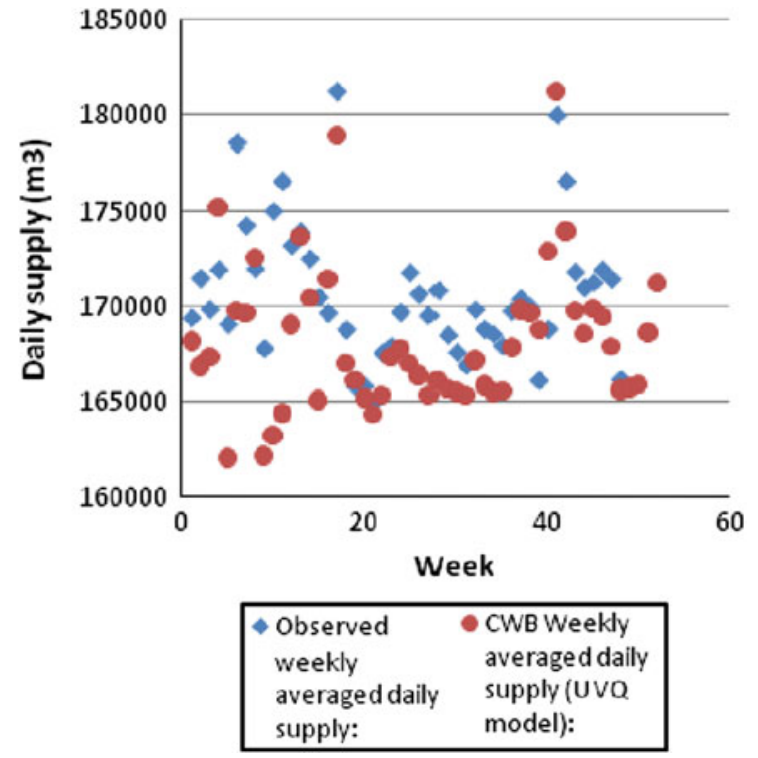

Fig. 3 Gross mains supply to the study area. Observed supply data versus CWB predicted during the period (April 2008 to March 2009)

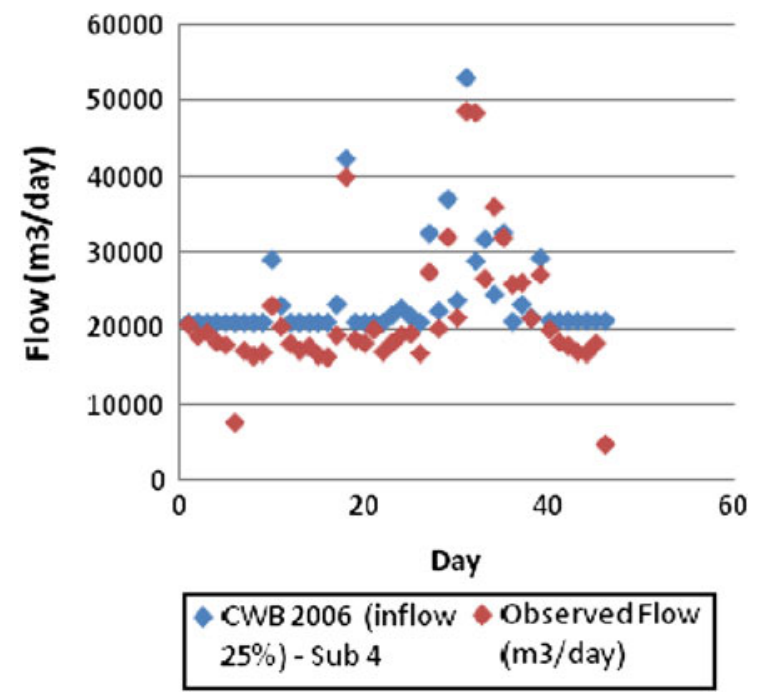

Fig. 4 Comparison of actual and CWB modelled wastewater flows from Subcatchment 4. Observed daily storm water flow versus CWB predicted for Sub 4 (April-June 2006)

main flows was reproduced and the high flows are also characterised.

As a validation exercise, these parameters were applied to flows observed at FlowMonitoring point FM03 near the downstream edge of Subcatchment 4 (Fig 4). Given the scoping level of the modelling, the results do not match the observations precisely, but 
they do provide evidence that significant aspects of the water demand and drainage are being captured by the simulations. They also provide indicators that different cities have rather different characteristics (notably in terms of wastewater) as indicated by the Doncaster comparison. The main observation from the results of the simulations presented for both initial and late calibration and validation is that with a relatively coarse description of the urban area employing a range of simplifying assumptions, it is possible to deliver an acceptable fit between the observed and predicted flows for the purpose of scoping the impact of changes to the urban water management in Birmingham.

$C W B$ is being further tested on several cities including Alexandria (Egypt), Dunedin (USA) and Accra (Ghana).

i). Also on Hamburg?

ii). Can you add reference to papers or reports published on these cities, e.g. Eu reports or UNESCO-IHE MSc reports?

\section{Conclusions}

City Water Balance has been developed to permit scoping calculations to be undertaken to assess the impact of different future scenarios and future urban water management strategies on a range of flow, quality, cost and energy indicators for a city. The model has been designed to be simple to establish and operate. Initial testing using data from Birmingham has demonstrated that the model is capable of reproducing the spatial and temporal characteristics of the flow systems for an urban area. It has also demonstrated that some aspects of the water distribution have significant uncertainties and account may need to be taken of these for exploration of future strategies prior to more detailed modeling with other tools.
Acknowledgments The authors would like to acknowledge the support of the European Union for the funding via the SWITCH project (018530-2)) to undertake the current research and to Severn Trent plc for the provision of the data characterizing the water supply and wastewater network for Birmingham.

\section{References}

DEFRA (2007) Guidelines to Defra's GHG conversion factors for company reporting [online]. [Accessed Feb 3rd 2010]. Available from the World Wide Web:<http://www.defra. gov.uk/environment/business/reporting/pdf/conversionfactors.pdf $>$

Hammond GP, Jones CI (2008) Embodied energy and carbon in construction materials. Proc Instn Civil Engrs: Energy 161(2):87-98

Hunt DVL, Lombardi DR (2006) Sustainable water supplies? A feasibility study for Birmingham eastside

Karka P, Manoli E, Lekkas DF, Assimacopoulos D (2006) A Case study on integrated urban water modelling using aquacycle. Proceedings of the 10th international conference on environmental science and technology. A629-639. Cos, Greece

Makropoulos CK, Natsis K, Liu S, Mittas K, Butler D (2008) Decision support for sustainable option selection in integrated urban water management. Environ Modelling Softw 23:1448-1460

Manoli E (2009) Personal communication

Mitchell VG, Diaper C (2005) UVQ User manual

Mitchell VG, Mein RG, McMAhon TA (2001) Modelling the urban water cycle. J Environ Modelling Softw 16:615-629

Mitchell VG, Diaper C, Gray SR (2003) UVQ: MOdelling the movement of water and contaminants through the total urban water cycle. The institution of engineers, Australia: 28th International hydrology and water resources symposium. Wollongong, NSW

Rueedi J, Cronin AA (2005) Case study city Doncaster: field investigations final report. AISUWRS Workpackage 10/4: UVQ Report

SPON (2005) Civil engineering and highways works pricing book

Woods-Ballard B, Kellagher R, Martin P, Jefferies C, Bray R, Shaffer P (2007) The SUDS manual. CIRIA Report 697 